\title{
Francisco Domínguez Matito, Juan Manuel Escudero Baztán y Rebeca Lázaro Niso (eds.), Mujer y sociedad en la literatura del Siglo de Oro, Madrid/Frankfurt, Iberoamericana/Vervuert, 2020, 327 pp. ISBN: 978-84-9192-173-8
}

\section{María Fernández Ferreiro}

https://orcid.org/0000-0002-6413-6404

Universidad de Oviedo

ESPAÑA

fernandezfmaria@uniovi.es

[Hipogrifo, (issn: 2328-1308), 9.2, 2021, pp. 1123-1127]

Recibido: 14-05-2021 / Aceptado: 04-06-2021

DOI: http://dx.doi.org/10.13035/H.2021.09.02.75

Vivimos, afortunadamente, en una época en la que se entiende a las mujeres como sujeto, y no como objeto, literario. Pero el tradicional relegamiento de la mujer a la esfera privada nunca ha impedido que existieran esas figuras femeninas que, gracias a la evolución social, hoy consideramos igual de importantes que sus homólogos masculinos. Esta es la perspectiva desde la que presentan este volumen, en la «Nota preliminar», sus editores: Francisco Domínguez Matito, Juan Manuel Escudero Baztán y Rebeca Lázaro Niso. Desde este punto de partida, es decir, desde la consideración de que en el Siglo de Oro también existieron personajes femeninos - reales o literarios - que van más allá de los tradicionales roles que ceñían a la mujer al ámbito doméstico, invisible y sumiso, es desde donde hay que situarse para comprender este volumen. «Haberlas, haylas»: mujeres protagonistas de sus propias vidas siempre las ha habido; lo que cada vez vemos con mayor frecuencia son estudios académicos sobre ellas. Este trabajo recopilatorio es un ejemplo de ello. 
Caracteriza el volumen, como es lógico, una considerable variedad temática. No obstante, se pueden rastrear algunas concomitancias entre varios de los capítulos, resultado del tema compartido por todos los autores, así como del trabajo unificador de los editores. Siguiendo esta idea, se plantea en las siguientes páginas una reseña ordenada no según el índice del libro, sino de acuerdo con estas relaciones entre estudios diversos.

El primer trabajo se centra en una de las cinco obras de temática bíblica de Tirso de Molina, La mujer que manda en casa. Roberta Alviti (pp. 9-29) analiza el protagonismo de Jezabel tanto en la estructura dramática de la obra -apoyándose en un detallado esquema- como en su composición textual, ya desde su mismo título, que plantea una selección consciente de tres variantes de un refrán de modo que el resultado final afirme que quien manda en la casa es la mujer.

Emmanuel Marigno (pp. 139-149), por su parte, dedica su estudio a otro autor reconocido: Calderón de la Barca. Critica el investigador la interpretación anacrónica que otros estudiosos (ejemplificados en Carolyn Morrow) han planteado sobre los textos del autor aurisecular en el marco de los estudios de género, así como la equiparación de texto literario con documento histórico, y termina reclamando más estudios sobre la producción literaria de las escritoras del Siglo de Oro y «menos polémica» (p. 148) sobre los personajes femeninos.

Uno de los autores más estudiados en este volumen, no obstante, es Álvaro Cubillo de Aragón, a quien un suceso histórico real, el episodio de los comendadores de Córdoba, le sirvió de inspiración para La mayor venganza de honor. Simón Sampedro Pascual (pp. 261-278) desglosa esta comedia junto a Los comendadores de Córdoba de Lope de Vega poniendo el foco en el tratamiento de la honra y el honor.

Por su parte, Rebeca Lázaro Niso (pp. 97-112) destaca el relevante papel de los personajes femeninos de carácter fuerte en el teatro del Siglo de Oro y analiza, específicamente, estas mujeres valientes y guerreras en dos dramas históricos y uno religioso de Álvaro Cubillo de Aragón: El conde de Saldaña, El rayo de Andalucía y Los desagravios de Cristo.

Maribel Martínez López (pp. 171-189) observa en estas mismas mujeres fuertes, inteligentes y valientes una visión protofeminista, y, como ejemplo, toma el personaje de Dionisia, protagonista de Añasco el de Talavera, también de Cubillo de Aragón, afirmando que «la obra puede ser interpretada desde las teorías de género y el enfoque actual del mismo, sin que ello desvirtúe la interpretación canónica áurea» (p. 183).

Alberto Escalante Varona (pp. 69-84), por su parte, aborda el cambio de la concepción de la mujer en escena en el siglo XVIII en comparación con la época barroca, centrándose asimismo en el tópico de la mujer guerrera. Se detiene el investigador en sendas obras de María Rosa Gálvez y María de Laborda, afirmando que el estereotipo mencionado, «a través del prisma femenino, tiene que pasar naturalmente por los códigos literarios y escénicos de la comedia sentimental burguesa» (p. 76) de la época y sufrir, por tanto, una lógica reinterpretación. 
Otra autora estudiada es Cecilia del Nacimiento, carmelita a caballo entre el siglo XVI y el XVII, una mujer de excepcional formación académica. De sus textos, Esther Borrego Gutiérrez (pp. 31-49) escoge para este trabajo un manuscrito perdido y dos relaciones de mercedes, los únicos tres escritos de Cecilia del Nacimiento de carácter autobiográfico, que la investigadora compara con el modelo de santa Teresa de Jesús y su Libro de la vida.

También a la producción literaria de una monja se dedica el siguiente capítulo, en el que Jesús Cañas Murillo (pp. 51-68) estudia las comedias profanas de sor Juana Inés de la Cruz, reclamando que los escritos de la autora novohispana tienen una condición polifacética que no siempre es reconocida y que va más allá del carácter profundo y serio con el que se identifica su obra.

Precisamente, en el estudio firmado por María Luisa Lobato y María Robles (pp. 113-138), las investigadoras afirman que gran parte de la producción escrita femenina de la Edad Moderna tiene origen conventual, de mano de unas pocas autoras cuya «voz es la expresión de muchas otras voces calladas» (p. 115). Entre estos textos, los más abundantes son los escritos en prosa de no ficción y, dentro de la ficción, los textos líricos. Lobato y Robles escogen para su trabajo, no obstante, aquellos escritos más relacionados con la teatralidad, muchos de ellos anónimos y que no fueron impresos; concretamente, un coloquio en prosa que recoge por escrito un diálogo, posiblemente real, entre seis religiosas carmelitas descalzas y que las investigadoras editan por completo en este volumen.

Por otro lado, otros tres trabajos plantean estudios comparativos. En el primero de ellos, Juan Antonio Martínez Berbel (pp. 151-169) comenta el episodio de Marcela en el Quijote (capítulos 11-14 de la primera parte), desvinculándose de la línea que interpreta el personaje en clave feminista por considerarla anacrónica, aunque equiparando la rebelión social de la pastora fingida a la del hidalgo. Tras presentar unos breves antecedentes del episodio cervantino, pasa a analizar una curiosa recreación dramática de dicha historia en La Arcadia en Belén y amor el mayor hechizo, una comedia bíblica neotestamentaria de Matos y Guzmán publicada entre 1671 y 1710, y las semejanzas y diferencias con el texto cervantino.

En el segundo, Miguel Nieto Nuño (pp. 213-228) confronta Jenofa Juncal, de Alfonso Sastre (escrita en 1983) con La serrana de la Vera de Luis Vélez de Guevara y se detiene en un repaso acto a acto del texto aurisecular, mostrando la evolución de la Serrana de heroína a mártir.

Por su parte, en el tercero de estos estudios comparativos, Isabel Sainz Bariain (pp. 243-259) hace un análisis de la percepción sobre el rol de la mujer casada en tres tratados del Siglo de Oro (La perfecta casada, de fray Luis de León; Instrucción de la mujer cristiana, de Juan Luis Vives; y Libro intitulado vida política de todos los estados de las mujeres, de fray Juan de la Cerda) antes de centrar su trabajo en la obra teatral que bebe de ellos y hereda su carácter didáctico: La perfecta casada, de nuevo de Cubillo de Aragón. 
Por último, varios estudios se centran en los personajes femeninos de la literatura aurisecular (ya vimos algunos sobre la mujer guerrera más arriba). Por un lado, Debora Vaccari (pp. 295-322) dedica un minucioso trabajo a los personajes de las graciosas y criadas (que no siempre son lo mismo) y, aun reconociendo la predominancia de sus homólogos masculinos, reclama mayor atención sobre los primeros. Explica la investigadora la relevancia de estos papeles en las compañías profesionales, valiéndose de fuentes tan útiles como el DICAT, y analiza estos papeles en algunas comedias de Moreto. Finalmente, recoge en un amplio apéndice todas las actrices localizadas en el DICAT en relación con las palabras graciosa o graciosidad.

Por otro lado, Juan Matas Caballero (pp. 191-211) analiza la figura de la mujer en cuarenta y dos sonetos circunstanciales de Góngora, estableciendo dos categorías funcionales para su estudio: personajes de la realidad, por un lado, y mujeres anónimas o tipos, por el otro, y con alguna remisión incluida a las décimas gongorinas. Tras una clarificadora conclusión donde recopila las características generales de estos poemas, termina sugiriendo que sería interesante comparar el tratamiento de la mujer observado en ellos con sonetos de otros autores u otros géneros líricos del mismo Góngora.

Por su parte, Victoriano Roncero López (pp. 229-241) afirma que las mujeres en la literatura picaresca eran caracterizadas por una sexualidad condenada moralmente y rastrea estos rasgos específicamente en los personajes del Guzmán de Alfarache de Mateo Alemán; unos personajes femeninos que funcionan, desde la perspectiva arrepentida del protagonista narrador, como un antimodelo de comportamiento.

Del mismo modo, Marcella Trambaioli (pp. 279-294) toma en su estudio los personajes femeninos de una obra concreta -en este caso, La hermosa Ester, de Lope de Vega- como base para analizar sus dimensiones pública y privada, partiendo de la idea de que la esfera doméstica, en el Siglo de Oro, es el espacio que corresponde a la mujer.

Finalmente, el capítulo firmado por Juan Manuel Escudero Baztán (pp. 85-95) supone un cambio temático considerable: en él, se pone el foco en los relatos documentales de crónica negra aurisecular, los cuales involucran tanto a hombres como a mujeres, y se recopilan variados ejemplos protagonizados por estas últimas, tan truculentos como curiosos, sacados de los Avisos de Barrionuevo.

Haciendo un repaso de todos los capítulos, aunque los estudios aquí publicados abarcan tanto personajes femeninos reales como literarios, la balanza numérica se inclina considerablemente de parte de los segundos. Solamente cuatro capítulos, de los diecisiete totales, se centran en autoras auriseculares. Los otros trece, por su parte, analizan distintas figuras femeninas ficcionales nacidas de manos de autores masculinos. No obstante, en dos de los cuatro mencionados se plantean sendas líneas de investigación interesantes para un futuro: por un lado, en el trabajo sobre Cecilia del Nacimiento, Borrego Sánchez reivindica los archivos conventuales y, por otro, Cañas Murillo propone replantear la visión canónica de sor Juana Inés de la Cruz para apreciar una escritora más lúdica y ligera. 
En resumen, los trabajos aquí recogidos analizan el rol de la mujer en la literatura española del Siglo de Oro desde distintas perspectivas y significan una relevante actualización de los estudios académicos al respecto. Se configura, así, un variado volumen que puede ayudar al lector no solo a conocer mejor el papel de la mujer en la literatura aurisecular sino, también, a reflexionar sobre él en la actualidad. 